\title{
A PROBABILISTIC ANALYSIS OF SILICON COST
}

Leonard J. Reiter

November 15, 1983

Prepared for

U.S. Department of Energy

Through an Agreement with

National Aeronautics and Space Administration

by

Jet Propulsion Laboratory

California Institute of Technology

Pasadena, California

JPL Publication 83-94 


\section{A PROBABILISTIC ANALYSIS OF SILICON COST}

Leonard J. Reiter

November 15, 1983

Prepared for

U S Department of Energy

Through an Agreement with

Natıonal Aeronautics and Space Admınistration

by

Jet Propulsion Laboratory

Calıfornia Institute of Technology

Pasadena, Calıfornıa

JPL Publication 83-94 
Prepared by the Jet Propulsıon Laboratory, Calıfornı Institute of Technology, for the U S Department of Energy through an agreement with the National Aeronautics and Space Admınıstratıon

The JPL Flat-Plate Solar Array Project is sponsored by the U S Department of Energy and is part of the Photovoltaic Energy Systems Program to initiate a major effort toward the development of cost-competitive solar arrays

This report was prepared as an account of work sponsored by an agency of the United States Government Neither the United States Government nor any agency thereof, nor any of their employees, makes any warranty, express or implied, or assumes any legal liability or responsibility for the accuracy, completeness, or usefulness of any information, apparatus, product, or process disclosed, or represents that its use would not infringe privately owned rights

Reference herein to any specific commercial product, process, or service by trade name, trademark, manufacturer, or otherwise, does not necessarıly constitute or imply its endorsement, recommendation, or favoring by the United States Government or any agency thereof The views and opinions of authors expressed herein do not necessarily state or reflect those of the Unted States Government or any agency thereof

This publication reports on work done under NASA Task RE-152, Amendment 66, DOE / NASA IAA No DE-AI01-76ET20356 
Silicon materials costs represent both a cost driver and an area where improvement can be made in the manufacture of photovoltaic modules. This study analyzes the cost from three processes for the production of low-cost silicon being developed under the U.S. Department of Energy's (DOE) National Photovoltaic Program. The approach is based on probabilistic inputs and makes use of two models developed at the Jet Propulsion Laboratory: SIMRAND (SIMulation of Research ANd Development) and IPEG (Improved Price Estimating Guidelines).

The approach, assumptions, and limitations are detailed in the study along with a verification of the cost analyses methodology. The results are presented in the form of cumulative probability distributions for silicon cost. These results indicate that there is a $55 \%$ chance of reaching the DOE target of $\$ 16 / \mathrm{kg}$ for silicon material. This is a technically achievable cost based on expert forecasts of the results of ongoing research and development and do not imply any market prices for a given year. 


\section{ACKNOWLEDGMENTS}

The author appreciates the kind assistance of the following persons at JPL: Anthony Briglio, Jr., and George C. Hsu helped in formulating this study and provided inputs to the data base. Joseph Glyman performed the analysis that validated the cost estimating methodology used in this study. Robert $W$. Aster, Paul K. Henry, and Ralph F. Miles, Jr., furnished guidance and direction during the course of this study. Milton L. Lavin reviewed this document thoroughly. Dorothy Johnson, Wendy Talbert, and Andrea Angrum, each of whom deserve congratulations for being able to read my handwriting, prepared this document. Thanks are also extended to those individuals at Union Carbide Corp. and Hemlock Semiconductor Corp. for taking the time to answer some questions. 


\section{GLOSSARY}

$\begin{array}{ll}\text { DCF } & \text { Discounted Cash Flow } \\ \text { DOE } & \text { U.S. Department of Energy } \\ \text { FBR } & \text { Fluidized-bed reactor } \\ \text { FSA } & \text { Flat-Pate Solar Array Project (at JPL) } \\ \text { IPEG } & \text { Improved Price Estimating Guidelines } \\ \text { JPL } & \text { Jet Propulsion Laboratory } \\ \text { PV } & \text { Photovoltaic(s) } \\ \text { R\&D } & \text { Research and development } \\ \text { ROE } & \text { Return on Equity } \\ \text { SAMICS } & \text { Solar Array Manufacturing Industry Costing Standards } \\ \text { SERI } & \text { Solar Energy Research Institute } \\ \text { SIMRAND } & \text { SIMulation of Research ANd Development (model) } \\ \text { TREI } & \text { Texas Research and Engineering Institute } \\ \text { UCC } & \text { Union Carbide Corp. }\end{array}$




\section{"Page missing from available version"}


1. INTRODUCTION. . . . . . . . . . . . . . . . . 1

2. APPROACH . . . . . . . . . . . . . . . . . . 3

A. $\operatorname{cost}$ estimating ....................... 3

B. DATA ENCODING ................... . . . . . 4

C. DATA ANALYSIS . . . . . . . . . . . . . 5

3. ASSUMPTIONS . . . . . . . . . . . . . . . . . . 7

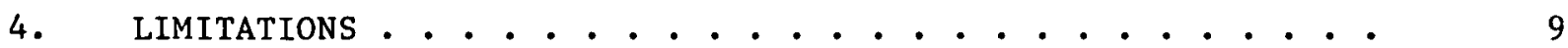

5. RESULTS AND IMPLICATIONS. . . . . . . . . . . . . . 11

6. CONCLUSIONS . . . . . . . . . . . . . . . . 15

REFERENCES •. . . . . . . . . . . . . . . . . . 17

APPENDIXES

A. CUMUlative PRobabilities ............. A .1

B. ECONOMIC ASSUMPTIONS ............... . . B-1

Figures

1. Cumulative Probability Distribution for Silicon Cost for Three Refinement Processes . . . . . . . .

2. Composite Silicon Cost for Three Refinement Processes in Competition . . . . . . . . . . . . . . .

3. Composite Silicon Cost for Two Refinement Processes in Competition (Fluidized-Bed Reactor Excluded) . . . .

4. Sensitivity of Silicon Cost to Its Major Cost Drivers.

1. Comparison of IPEG and Lamar University/Texas Research and Engineering Research Results for Silicon Costs From Several Refinement Processes. . . . . . . . . 


\section{SECTION 1}

\section{INTRODUCTION}

The reduction of silicon cost has long been a goal of the U.S. Department of Energy's (DOE's) National Photovoltaics Program as part of the effort to develop cost-effective photovoltaic (PV) systems. The majority of silicon used by the PV industry comes from manufacturers whose market is primarily the semiconductor industry (E. Costague, et al., 1979 and 1983, References 1 and 2), for whom silicon cost is not a cost driver. The National Photovoltaics Five-Year Research Plan (DOE, 1983, Reference 3) describes DOE's support of research and development on processes that will produce low-cost silicon for use by the PV industry. Cost analyses have been done by Lamar University (C. Yaws, et a1., 1981, Reference 4) and the Texas Research and Engineering Institute (TREI, 1982, Reference 5) to determine the price of mass-produced silicon from some of these processes. The study described in this report is unique in its approach because a probabilistic cost analysis was done.

The idea for this probabilistic cost analysis of refined silicon arose from the combined Jet Propulsion Laboratory (JPL) and Solar Energy Research Institute (SERI) silicon sheet material assessment (JPL/SERI, 1982, Reference 6 ), which was one of the earliest probabilistic studies in the PV Program. The next step for this study was to extend the analysis to the component processes and the major cost factors in silicon module manufacturing. Because semiconductor-grade silicon manufacturing costs had never been subjected to a detailed analysis, it was decided that the refinement processes warranted such a study.

Previous cost analyses of silicon refinement that were performed by various contractors and consultants have been based on point estimates for the cost inputs rather than ranges or probabilistic distributions. These estimates were reasonable in light of the input data; however, point estimates lie within a range of possible costs, but contain no information as to the scope of this range or to the relative location of the estimate within that range. One cannot assume that an estimate represents the median, mean, or any other point on a distribution of possible outcomes. By encoding cumulative probability distributions for the cost variables, where the probabilities for each variable are based on consistent assumptions, this information is accessible and is carried through to the result which is a cumulative probability distribution of silicon price.

The current Five-Year Research Plan (DOE, 1983, Reference 3) calls for the demonstration of production processes for low-cost silicon by 1988 . Low cost is defined as under $\$ 20 / \mathrm{kg}$ with a target of $\$ 16 / \mathrm{kg}$, each expressed in 1982 dollars. Early in the PV Program, the Silicon Materials Task of JPL's Flat-Plate Solar Array Project supported research on ten different processes. As the research progressed, the options narrowed down to only three processes that are now being studied: two silane processes from Union Carbide Corp. (Union Carbide, 1983, Reference 7) and one dichlorosilane process from Hemlock Semiconductor Corp. (Hemlock, 1983, Reference 8). The silane process is currently utilizing a Siemens-type (Komatsu) reactor for silane conversion to silicon, while research on a fluidized-bed-reactor (FBR) process has continued within the Program. 
These three processes were chosen to be analyzed for this report because it would have been very difficult to obtain data from sources outside the DOE PV Program. As it was, certain data were not made available for the chosen processes because of proprietary reasons. The results, then, reflect the likelihood of the DOE PV Program achieving its stated cost goals, and may also serve as a useful data base for future planning exercises or analyses in which silicon cost plays a part.

The study involved several stages. Initially, an approach needed to be developed and the tools chosen for that approach had to be verified for this application. This process is detailed in Section 2. As with any study, the particular approach implies certain assumptions and limitations, which are discussed in Sections 3 and 4, respectively. The bulk of the work involved encoding data from appropriate sources and performing a probabilistic analysis based on that data. The results of this analysis are in the form of probabilistic distributions for silicon cost and are seen in section 5, along with a discussion of their implications. The usefulness of these results lie mainly in their impact on PV module and systems costs, and their insight into the effectiveness of PV in comparison to other generation technologies. Section 6 summarizes the results and implications, and offers some suggestions for future investigations. 


\title{
SECTION 2
}

\author{
APPROACH
}

\section{A. COST ESTIMATING}

Cost estimating in this study was accomplished by using the Improved Price Estimating Guidelines (IPEG) methodology ( $R$. Aster and R. Chamberlain, 1980, Reference 9), which was derived from the SAMICS (Solar Array Manufacturing Industry Costing Standards) model (JPL, 1981, Reference 10). The IPEG method is fast and relatively easy to use, yet it had never been validated for the silicon refinement process. The validation was executed as the first part of this study. Previous analyses of silicon cost results had been performed for the PV Program by Lamar University (C. Yaws, et al., 1981, Reference 4) and TREI (1982, Reference 5), using standard chemical industry costing methods. The IPEG results using identical inputs and assumptions for several different silicon production processes were compared with the Lamar/ TREI results, which are shown in Table 1 (in 1980 dollars). The Return on Equity (ROE) used in IPEG closely resembles the Discounted Cash Flow (DCF) used by Lamar/TREI. These results demonstrated that IPEG could be used for this study. On the average, the difference between the two methods was only $2.6 \%$.

The IPEG equation includes inputs for equipment costs, square footage of manufacturing floor space, materials costs, utilities costs, labor costs, and output quantity. For this study, a reference output capacity of 1000 metic tons per year was chosen for use throughout the analysis. Preliminary results produced from inputs used in the validation were sensitive to square footage of floor space. This seemed unreasonable for a chemical processing plant since reductions in plant area should not have a large effect on product cost. The problem arose because the square footage parameter reflects floorspace costs for the manufacturing equipment and was not appropriate for a chemical processing plant where the distinction between manufacturing equipment and support facilities is not well defined. Instead, the entire plant was modeled as if it were a piece of depreciable equipment. This resulted in a model yielding the results in Table 1 , which are consistent with physical intuition and the relative importance of the cost drivers examined in previous studies.

This cost-estimating methodology was then incorporated into the probabilistic analysis. Probabilistic distributions were used as inputs to the IPEG equation. In the case of equipment cost, the processes were separated into sections and distributions were encoded for each one. Each section represented a step in the silicon purification process. Similarly, utilities cost was encoded by type (i.e., electricity, steam, etc.). These were aggregated to produce the total input. For materials costs and labor costs, the total input for the process was encoded directly since breakdown by process step was more difficult. This strategy captured the essence of the economics of the processes while keeping the data encoding and analysis task workable. Items such as recycle loops were not modeled separately, but their influence on plant economics can be seen through the impact on other inputs. 
Table 1. Comparison of IPEG and Lamar University/Texas Research and Engineering Research Results for Silicon Costs From Several Refinement Processes

\begin{tabular}{|c|c|c|c|}
\hline Process & $\begin{array}{c}\text { Lamar/TREI Price, } \\
\$ / \mathrm{kg} \text { at } \\
20 \% \text { DCF }\end{array}$ & $\begin{array}{l}\text { IPEG Price, } \\
\$ / \mathrm{kg} \text { at } \\
20 \% \text { ROE }\end{array}$ & $\begin{array}{c}\text { Percentage } \\
\text { Difference } \\
\text { From Lamar/TREI }\end{array}$ \\
\hline $\begin{array}{l}\text { Polysilicon } \\
\text { (conventional) }\end{array}$ & $\mathrm{N} / \mathrm{A}$ & $107.98^{a}$ & - \\
\hline $\operatorname{Sil}_{4}$ & 106.47 & 102.47 & 3.3 \\
\hline $\begin{array}{l}\text { Union Carbide } \\
\text { Silane }\end{array}$ & 13.65 & 13.59 & 0.5 \\
\hline Battelle BCL-A & 17.53 & 17.39 & 0.8 \\
\hline Battelle BCL-B & 15.55 & 15.46 & 0.6 \\
\hline Hemlock HSC-A & 33.80 & 32.06 & 5.2 \\
\hline Hemlock HSC-B & 33.73 & 32.00 & 5.1 \\
\hline
\end{tabular}

\section{B. DATA ENCODING}

The data encoding steps of a probabilistic analysis present the greatest challenge to the analyst. People are simply not accustomed to thinking probabilistically. Studies have shown that subjective terms, such as possible, probable, or likely, have drastically different meanings for different people. To avoid such confusion, data encoding must be done carefully and systematically. Many papers have been written on the subject of data encoding and the difficulties inherent in the process (R. Hogarth, 1975, Reference 11; and C. Spetzler and C. Stael Von Holstein, 1976, Reference 12). In this study questions were posed in a manner designed to avoid some of the comron pitfalls of encoding.

The experts interviewed for this study were asked a series of questions regarding a variable. These queries were posed in one of two ways: "What is the probability that the variable will be below a (given) value?" or "What value of the variable corresponds to a (given) probability level for that variable?" To avoid bias toward the median, the range of each distribution was established first. As each expert responded to the series of questions, the cost versus probability points were plotted on a graph. A cumulative probability distribution resulted from these questions. This was shown to each expert who then revised the data as needed. 
It was advantageous to the encoding process to break the variables down into component parts, when possible, as was done for equipment costs and utilities costs. Disaggregating the variables added an extra level of detail to the analysis and was helpful in preventing a bias from entering the distributions. The latter could result from the experts being overly familiar with data in a certain format and, therefore, being able to judge what the implications of their responses would be on the final result. Disaggregating the variables forced the expert to think about familiar data in new terms.

A distribution for each variable was initially encoded based on data from experts within JPL. The results from a complete analysis based on these data was reviewed revealing some inconsistencies in the data and misunderstandings in the encoding process. A second encoding round refined the data and included input from the companies whose processes were involved. For those cases where the inputs differed between industry and JPL, a compromise distribution was developed. For some variables proprietary restitutions forced the industry representatives to limit their inputs to ranges of values or brief comments on the JPL distributions.

Seventeen of these distributions were encoded using this methodology. These data formed the basis for the remainder of the analysis. Appendix A contains a listing of these distributions in tabular form.

\section{DATA ANALYSIS}

To perform arithmetic operations using probabilistic inputs in a practical manner, one needs a numerical method to approximate the analytical solutions. In this study the SIMRAND model (R. Miles, 1981 and 1982, References 13, 14, and 15) was used. This Monte Carlo simulation model can include equations, and perform the necessary operations using probabilistic inputs. Without such a tool, this type of study would be totally impractical. The model was used on two levels for this analysis. First, the inputs which had been encoded by process step, in the case of equipment cost, and by utility type, for utility costs, were sumed to produce the total inputs for the entire process. Secondly, after partial inputs had been summed, SIMRAND was used again to calculate silicon price, using the total inputs and the IPEG equation. The final result was a cumulative probability distribution on silicon cost. 


\section{Page intentionally left blank}

Page intentionally left blank 
As in any analysis, certain conditions were assumed as a basis for this study. The process plants were assumed to be the second or third ones of their kind built, (i.e., not prototypes), thus eliminating many of the uncertainities involved in a first-of-its-kind facility. The time frame is not defined as a specific year, but rather as the time when these plants are in a steady-state production mode at a level of 1000 metric tons per year. Adequate DOE funding to complete the R\&D taking place throughout the National PV Program is assumed to be available. This is likely to be the case because the JPL Silicon Materials Task R\&D Program is in its later stages.

Some economic assumptions had to be made in order to perform this analysis. The equipment lifetime is assumed to be 10 years. Income taxes and property taxes are $50 \%$ and $2 \%$ respectively, and business investment tax credits are included as we 11 . The rate of return on equity is assumed to be $20 \%$. The remaining assumptions are numerous and do not have a large effect on the results. All of the economic assumptions are summarized in.Appendix B, and many can be found in the IPEG User's Guide (P. Firnett, 1980, Reference 16).

The cost-accounting methodology used to calculate IPEG input values was based upon that used in the Lamar University and TREI studies. Total plant investment was derived from total equipment cost via a set of multipliers developed by the authors of those studies. These multipliers are fairly standard in chemical processing plant cost accounting and are based on years of empirical data.

Contingencies are assumed to be $15 \%$ of the total equipment cost. This number is consistent with SAMICS (JPL, 1981, Reference 10). 


\section{Page intentionally left blank}

Page intentionally left blank 
Probabilistic analyses require a large amount of data. Seventeen distributions had to be encoded, each of which was based upon a number of data points, in order to have one opinion for each variable. It was difficult to obtain several opinions from various experts for such a large amount of data. As previously mentioned, the experts from industry were unable to comment on some of the most uncertain variables because of their proprietary nature. Thus, in some cases, the uncertainty of a variable consisted not only of the inherent unknowns concerning the future but also of uncertainties in the data itself caused by a lack of expert input. For instance the proprietary Union Carbide Komatsu reactor process results cover a broader range than might have been necessary, given access to more precise equipment cost data.

This study does not consider market fluctuation effects on the price of silicon, but rather presents a price based on technology's achievements including a healthy (20\%) return on equity. In the past the price of silicon has varied with the cycles of shortages and gluts in the market. Accounting for market effects, corporate strategies, and other forces impacting the actual future price of silicon is beyond the scope of this study (see References 1 and 2 for silicon market price projections). The results do not represent a prognostication for future actual silicon prices. It is intended that the results will shed light on the achievability of the DOE Program goals. 


\section{Page intentionally left blank}

\section{Page intentionally left blank}




\section{SECTION 5}

\section{RESULTS AND IMPLICATIONS}

Figure 1 shows the results of the analysis. The three cumulative probability curves of price per kilogram of silicon represent the range of price anticipated for the Union Carbide silane processes (using the FBR and Komatsu reactor as labeled) and the Hemlock Semiconductor process. The curves extend, from lower left to upper right, from the most optimistic to the most pessimistic scenarios for each technology. The vertical axis represents cumulative probability from 0 to $100 \%$. A point on the curve portrays the probability that the technology will be capable of producing silicon at less than or equal to that cost.

The prospects for reaching the DOE cost goal looks promising for the Union Carbide FBR process. There is greater than a $90 \%$ chance that the product from the FBR process will be less than $\$ 20 / \mathrm{kg}$, the DOE definition for "low cost" (DOE, 1983, Reference 3). There is a $55 \%$ chance of meeting the $\$ 16 / \mathrm{kg}$ target price with this technology.

The Union Carbide Komatsu process and the Hemlock Semiconductor process show less of a chance of being "low cost". The results show a $10 \%$ and $5 \%$ chance of producing silicon at $\$ 20 / \mathrm{kg}$ or less for the Hemlock and Union Carbide processes, respectively. The Hemlock process, however, does show a greater than $90 \%$ chance of being $\$ 27 / \mathrm{kg}$ or less. For the Union Carbide Komatsu process, the $90 \%$ leve 1 is $\$ 34 / \mathrm{kg}$.

Figure 2 presents a different view of silicon price. Instead of a technology by technology breakdown of price distributions, silicon price is presented as an entity independent of technologies. SIMRAND allows all of the technologies to compete in a market-type situation. Points from each of the curves in Figure 1 are selected at random and compared for the least cost. The "winner" becomes part of the composite curve. This was done for 2500 scenarios. All three technologies were included, plus a "default" value of $\$ 60 / \mathrm{kg}$ for conventional process silicon. This default value corresponds to the price of silicon from available technologies today and represents the case where all research efforts "fail" or do not achieve technical success. A $2 \%$ chance of failure is included for the Hemlock and Union Carbide Komatsu processes, while a $5 \%$ chance of failure is included for the Union Carbide FBR process, reflecting the relatively larger uncertainty in this latter process. The default value is reached only when all technologies fail to reach technical success in the same scenarios. The very low probability associated with this event reflected in the immediate drop off from $\$ 60 / \mathrm{kg}$ at $10 \%$ to $\$ 25 / \mathrm{kg}$ at $99 \%$.

The FBR process dominates this graph as one might have expected. In $94 \%$ of the possible future scenarios produced for this graph, the FBR had the lowest priced product. Since the other two processes are likely to reach technical success before the FBR process, a composite graph excluding the FBR process is interesting as a picture of possible nearer-tern technically achievable silicon prices. This is presented in Figure 3. Once again, the default of $\$ 60 / \mathrm{kg}$ was used with a $2 \%$ probability of failure to achieve technical success for each process. The resulting graph closely resembles the Hemlock result from Figure 1. In $82 \%$ of the scenarios for this graph, Hemlock had the lower price. 


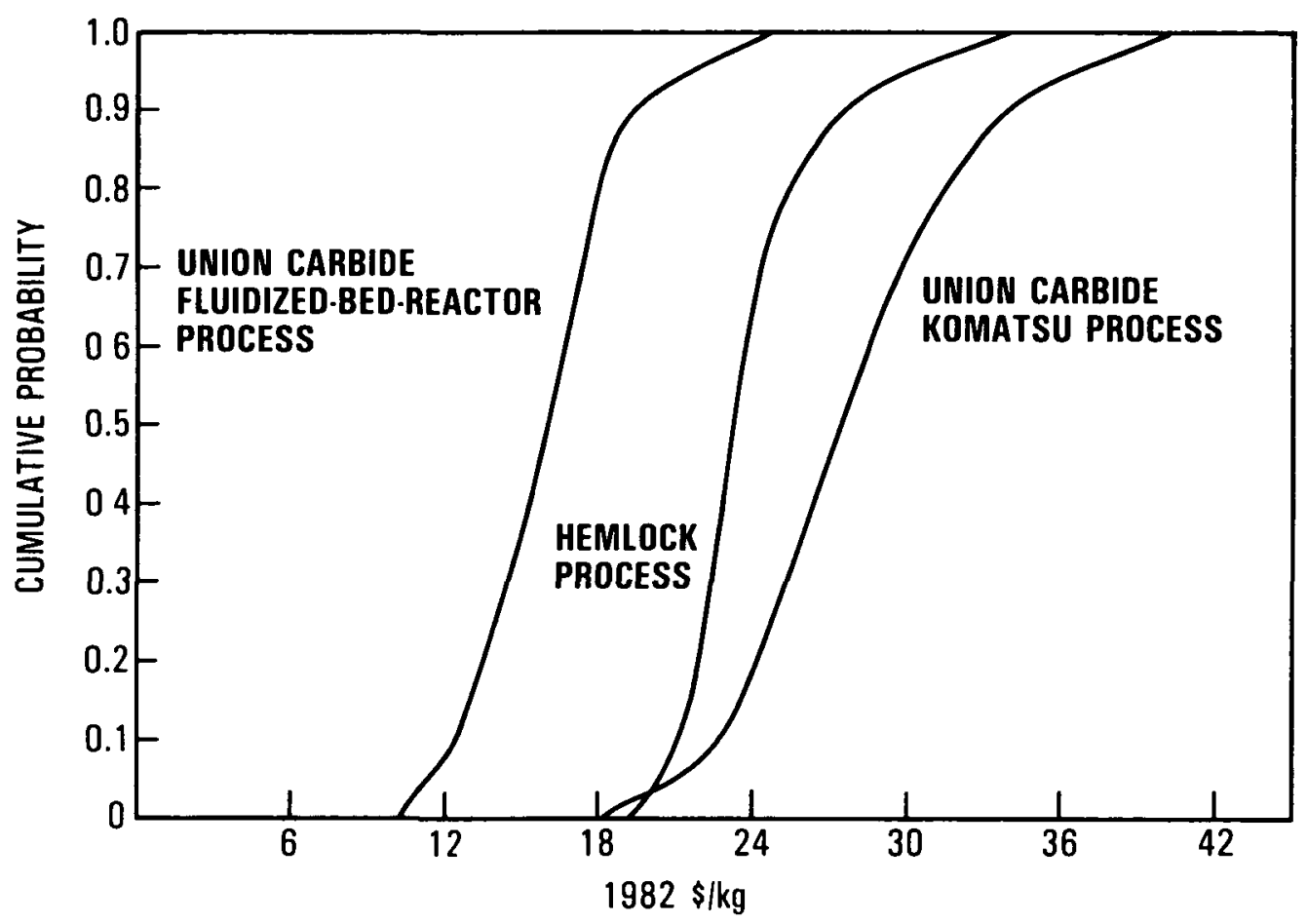

Figure 1. Cumulative Probability Distribution for Silicon Cost for Three Refinement Processes

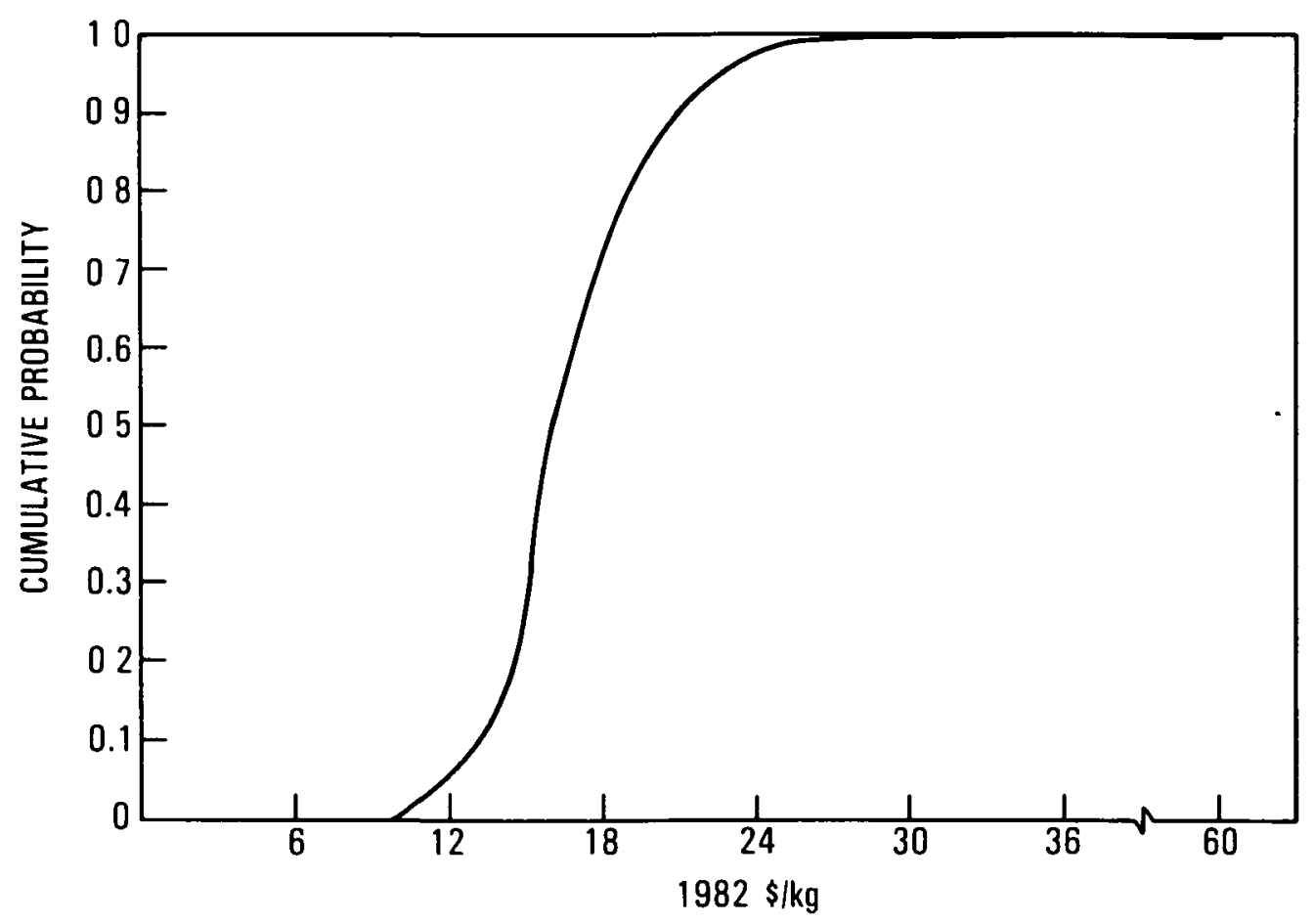

Figure 2. Composite Silicon Cost for Three Refinement Processes in Competition 


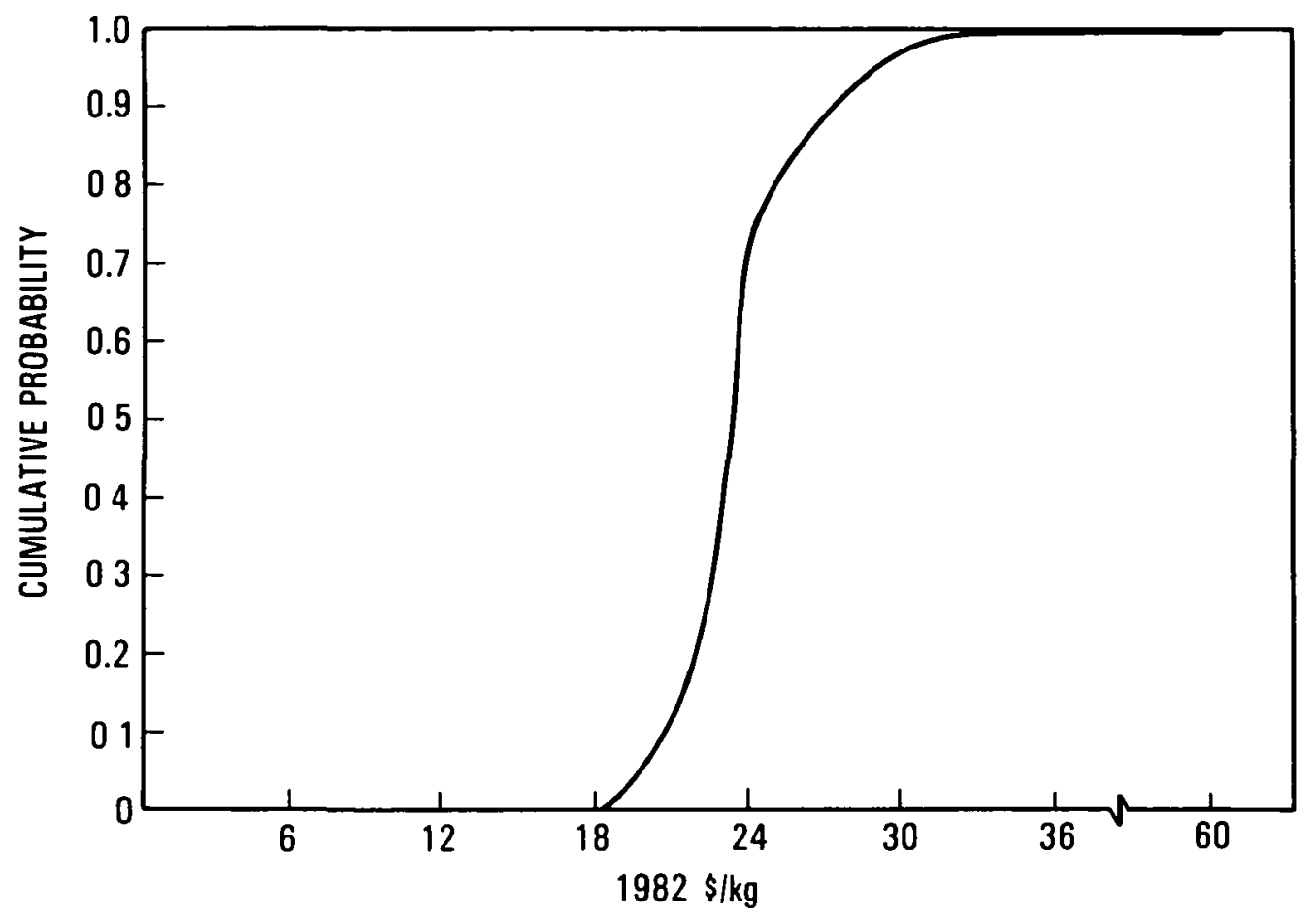

Figure 3. Composite Silicon Cost for Two Refinement Processes in Competition (Fluidized-Bed Reactor Excluded)

Figure 4 shows a sensitivity analysis of the four variables in the IPEG equation for the three processes. For each silicon purification process, a baseline case was calculated using median ( $50 \%$ probability) values for each variable. Each variable was then allowed to range from its highest to lowest value while the other variable remained constant at their median values. The bar graphs in Figure 4 are the result. In each case, the total plant investment (based on the multipliers referred to above) is the major factor. These capital costs account for greater than half the cost of the product while the expenses for utilities, material, and labor combined are the rest. The graph shows the relative uncertainty of the variables, because the size of each bar depends upon both the median of the distribution and the range above and below the median. 


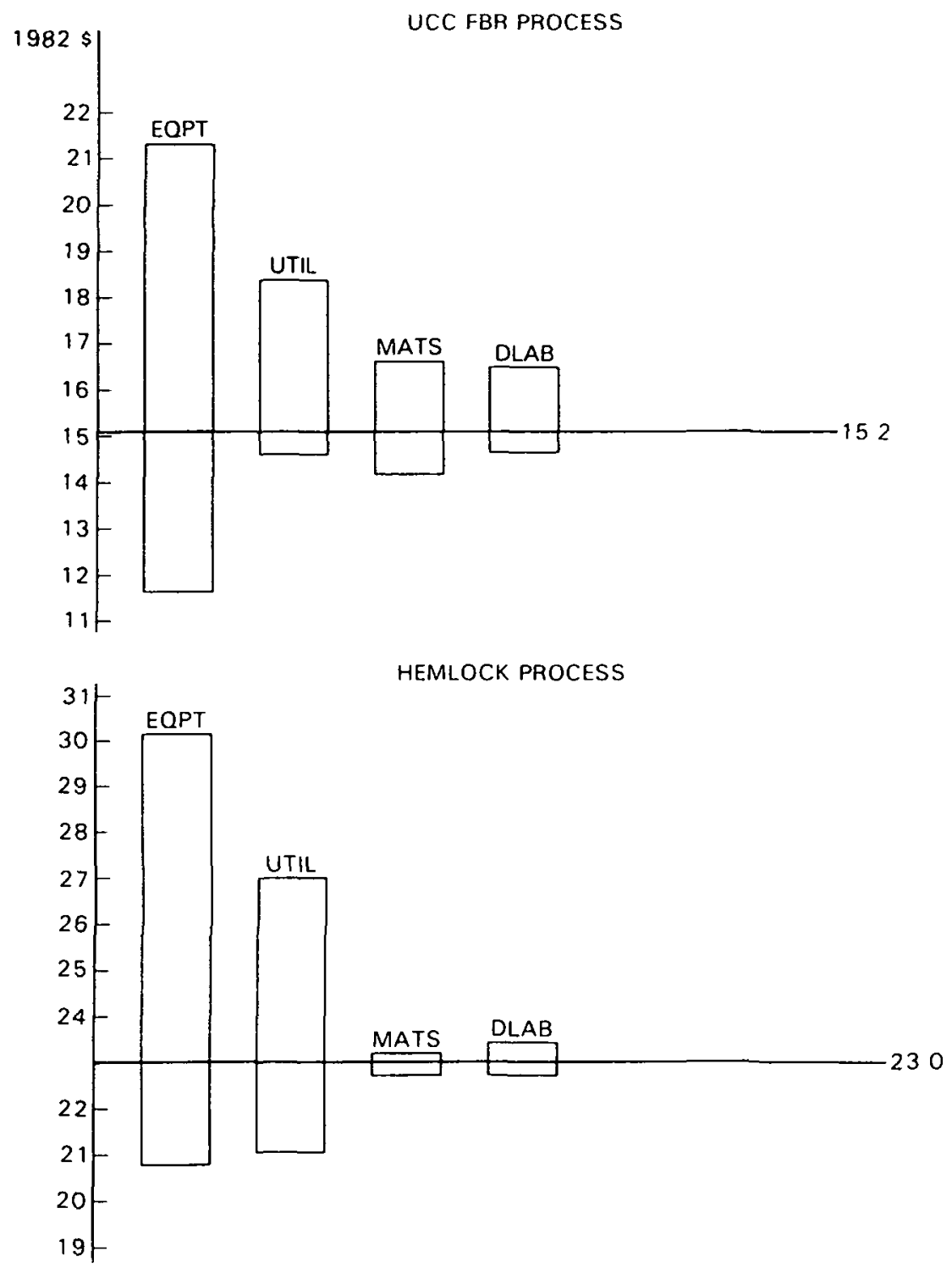

UCC KOMATSU PROCESS

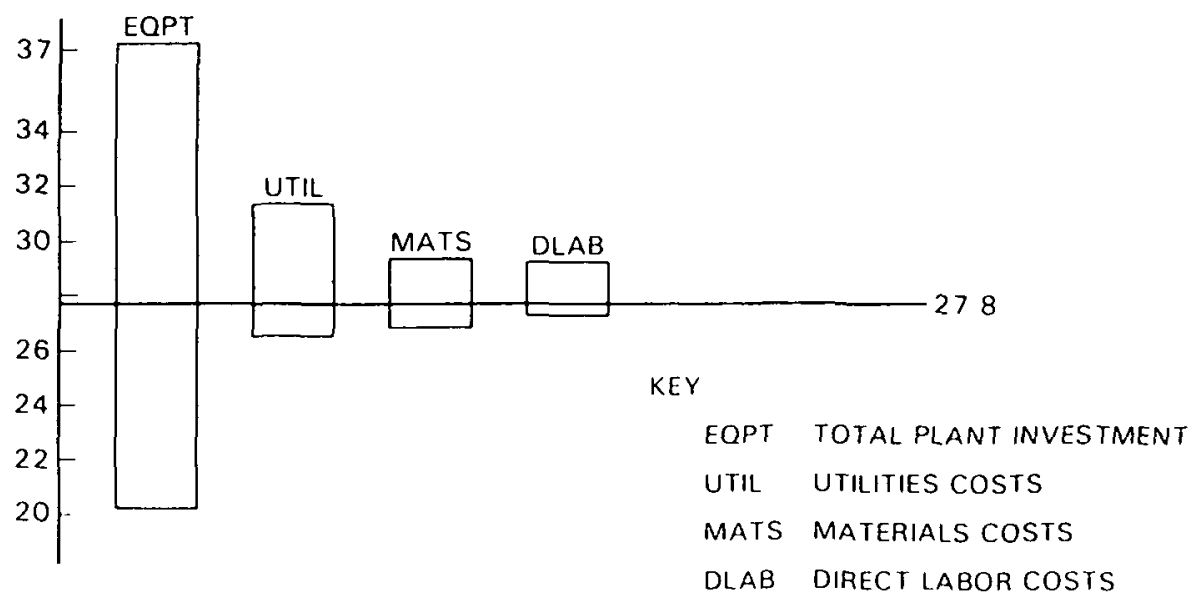

Figure 4. Sensitivity of Silicon Cost to Its Major Cost Drivers 


\section{SECTION 6}

\section{CONCLUSIONS}

The results of this study show that there is a better than $50 \%$ chance that the Silicon Materials Task of JPL's Flat-Plate Solar Array Project will meet its goal of $\$ 16 / \mathrm{kg}$ silicon (in 1982 dollars). This figure is based on technical achievement and does not consider market fluctuations or strategic corporate decisions. It seems that the FBR silane process from Union Carbide clearly has the best chance of being the process that produces this low-cost silicon. The Hemlock Semiconductor process and the Union Carbide silane process using a Komatsu reactor also showed promising results. The former shows a $10 \%$ chance of being $\$ 20 / \mathrm{kg}$ or less and a $90 \%$ chance of being $\$ 27 / \mathrm{kg}$ or less, while the latter resulted in a $5 \%$ chance of being $\$ 20 / \mathrm{kg}$ or lower and a $90 \%$ chance of being below $\$ 34 / \mathrm{kg}$. All of these processes offer significant decreases in the cost of semiconductor-grade silicon. Also, it should be noted that complementary research is being conducted in crystal growth and other PV processing steps to increase the utilization efficiency of silicon, thereby reducing the sensitivity of final PV module price to the price of silicon.

Although these silicon cost probability distributions are the primary results of this study, the methodology used to produce them is also of prime importance. The probabilistic approach yields more information than that of a cost analysis based on point estimates of component costs. The input data encoding phase demanded that each variable be investigated in detail. For each input, a range was established and a distribution was created capturing the inherent uncertainty which exists in all prognostications of cost for developing technologies. The results reflect this uncertainty, yet they show the future's technically achievable cost within a range discussed.

It seems that this methodology, which has proved itself useful in this study, could be applied to other cost-driving steps in the module manufacturing process. Cell metallization, cell sheet growth (including the deposition of thin films), and cell encapsulation (especially as it impacts module durability) seem to lend themselves well to such an analysis to quantify the uncertainty and potential of important processes. At the system level, issues such as operation and maintenence strategies and module installation might be investigated using such an approach as well. 


\section{Page intentionally left blank}

\section{Page intentionally left blank}


1. Costogue, E., et al., Silicon Materials Outlook Study for 1980-85 Calendar Years, JPL Document 5230-1, Rev. A, JPL Publication 79-110, DOE/JPL-1012-33, Jet Propulsion Laboratory, Pasadena, California, 1979.

2. Costague, E., and Pellin, R., Polycrystalline Silicon Material Availability and Market Pricing Outlook Study for 1980-88, JPL Document 5230-10, JPL Publication 83-9, DOE/JPL-1012-79, Jet Propulsion Laboratory, Pasadena, California, 1983.

3. National Photovoltaics Program Five Year Research P1an, U.S. Department of Energy, Washington, D.C., 1983.

4. Yaws, C., et al., Process Feasibility Study in Support of Silicon Material Task 1, Fina1 Report, JPL Document 9950-502, DOE/JPL 954343-81/21, Lamar University, Beaumont, Texas, 1981.

5. Silicon Production Process Evaluations, Final Report, JPL Document 9950-713, DOE/JPL-956045-8215, Texas Research and Engineering Institute, Inc., Port Neches, Texas, 1982.

6. Probabalistic Assessment of the Potential for Various Silicon Sheet Materials to Attain a Given Price, an unpublished report, Jet Propulsion Laboratory, Pasadena, California, and Solar Energy Research Institute, Golden, Colorado, 1982.

7. Experimental Process System Development Unit for Producing Semiconductor-Grade Silicon Using the Silane-to-Silicon Process, Final Report, Phase III, JPL Document 9950-837, DOE/JPL 954334-21, Union Carbide Corporation, Washougal, Washington, 1983.

8. Development of a Polysilicon Process Based on Chemical Vapor Deposition, Final Report, Phases I and II, JPL Contract 955533, Hemlock Semiconductor Corporation, Hemlock, Michigan, to be published.

9. Aster, R., and Chamberlain, R., Improved Price Estimating Guidelines (IPEG) Design Document, JPL Internal Document 5101-158, Rev. A, Jet Propulsion Laboratory, Pasadena, California, 1980.

10. Solar Array Manufacturing Industry Costing Standards (SAMICS): Short Course, JPL Internal Document 5101-196, Jet Propulsion Laboratory, Pasadena, California, 1981.

11. Hogarth, R., "Cognitive Processes and the Assessment of Subjective Probability Distributions," American Statistical Association Journal, Vo1. 70, No. 350, 1975.

12. Spetzler, C., and Stael Von Holstein, C., "Probability Encoding in Decision Analysis," Readings in Decision Analysis, Stanford Research Institute, Menlo Park, California, 1976. 
13. Miles, R., Jr., "Fortran Code for the SIMRAND Computer Program Version 3.0," JPL Interoffice Memorandum 311.2-368, Jet Propulsion Laboratory, Pasadena, California, 1981.

14. Miles, R., Jr., Introduction to SIMRAND, JPL Document 5101-204, JPL Publication 82-20, DOE/JPL 1012-68, Jet Propulsion Laboratory, Pasadena, California, 1982 .

15. Miles, R., Jr., The SIMRAND Methodology, JPL Internal Document 5101-213, Jet Propulsion Laboratory, Pasadena, California, 1982.

16. Firnett, P., Improved Price Estimating Guidelines (IPEG) Computer Program User's Guide, JPL Internal Document 5101-156, Rev. A, Jet Propulsion Laboratory, Pasadena, California, 1980. 
Seventeen distributions that were used in this analysis are shown below in tabular form. The percentages in each table represent cumulative probabilities. The probability data points vary in some of the tables as the shape of the distribution demands. Thus, each distribution $c$ an be sketched as a piece-wise linear fit of these data points. All of the data is for a 1000-ton-per-year plant, in 1980 dollars. A multiplier of 1.2 is used to convert 1980 dollars to 1982 dollars.

\begin{tabular}{ll}
$\%$ & $\begin{array}{l}\text { Hemlock Equipment Costs, } \\
\text { Hydrogenation Process }\end{array}$ \\
\hline & \\
0 & $\$ 600,000$ \\
10 & $\$ 625,000$ \\
25 & $\$ 650,000$ \\
50 & $\$ 700,000$ \\
75 & $\$ 750,000$ \\
90 & $\$ 875,000$ \\
100 & $\$ 950,000$
\end{tabular}

\begin{tabular}{ll} 
& $\begin{array}{l}\text { Hemlock Equipment Costs, } \\
\text { Redistribution Process }\end{array}$ \\
\hline 0 & $\$ 270,000$ \\
10 & $\$ 285,000$ \\
25 & $\$ 300,000$ \\
50 & $\$ 320,000$ \\
75 & $\$ 350,000$ \\
90 & $\$ 400,000$ \\
100 & $\$ 420,000$
\end{tabular}

Hemlock Equipment Costs, $\% \quad$ Modified Siemens Process

\begin{tabular}{ll} 
& Hemlock Equ \\
$\%$ & Waste/Recov \\
\hline 0 & $\$ 900,000$ \\
15 & $\$ 1,000,000$ \\
50 & $\$ 1,150,000$ \\
75 & $\$ 1,200,000$ \\
85 & $\$ 1,300,000$ \\
90 & $\$ 1,500,000$ \\
100 & $\$ 1,600,000$
\end{tabular}




\begin{tabular}{ll} 
& $\begin{array}{l}\text { Union Carbide } \\
\text { Equipment Costs, } \\
\text { Silane Process }\end{array}$ \\
\hline & \\
0 & $\$ 1,500,000$ \\
20 & $\$ 2,000,000$ \\
50 & $\$ 2,500,000$ \\
60 & $\$ 3,000,000$ \\
80 & $\$ 3,500,000$ \\
90 & $\$ 3,750,000$ \\
100 & $\$ 4,500,000$
\end{tabular}

\begin{tabular}{ll}
$\%$ & $\begin{array}{l}\text { Union Carbide } \\
\text { Equipment Costs, } \\
\text { Komatsu Process }\end{array}$ \\
\hline 0 & $\$ 3,000,000$ \\
10 & $\$ 3,500,000$ \\
30 & $\$ 4,000,000$ \\
50 & $\$ 5,000,000$ \\
70 & $\$ 5,500,000$ \\
90 & $\$ 6,500,000$ \\
100 & $\$ 7,000,000$
\end{tabular}

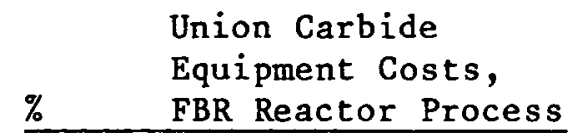

$0 \$ 450,000$

10 \$ 550,000

$25 \$ 600,000$

50 \$ 850,000

$75 \$ 1,100,000$

$90 \$ \$ 1,400,000$

$100 \$ \$ 1,700,000$

\begin{tabular}{ll} 
& $\begin{array}{l}\text { Hemlock } \\
\text { Utilities Costs, } \\
\text { Electricity } \\
(\mathrm{kWh} / \mathrm{kg})\end{array}$ \\
$\%$ & \\
\hline 0 & 68 \\
10 & 72 \\
25 & 76 \\
50 & 84 \\
75 & 90 \\
90 & 95 \\
100 & 100
\end{tabular}

\begin{tabular}{ll} 
& $\begin{array}{l}\text { Hemlock } \\
\text { Utilities Costs, } \\
\text { Other Utilities } \\
(\$ / \mathrm{kg})\end{array}$ \\
$\%$ & \\
\hline 0 & $\$ 0.43$ \\
5 & $\$ 0.45$ \\
25 & $\$ 0.50$ \\
50 & $\$ 0.55$ \\
70 & $\$ 0.60$ \\
90 & $\$ 0.66$ \\
100 & $\$ 0.70$
\end{tabular}

\begin{tabular}{ll} 
& $\begin{array}{l}\text { Hemlock \& Union Carbide } \\
\text { Utilities Costs, } \\
\text { Electricity } \\
(\$ / \text { kWh })\end{array}$ \\
$\% \quad$ & \\
\hline 0 & $\$ 0.023$ \\
5 & $\$ 0.025$ \\
30 & $\$ 0.030$ \\
50 & $\$ 0.036$ \\
75 & $\$ 0.043$ \\
90 & $\$ 0.050$ \\
100 & $\$ 0.060$
\end{tabular}

\begin{tabular}{ll} 
& $\begin{array}{l}\text { Union Carbide } \\
\text { Utilities Costs, } \\
\text { Electricity -- } \\
\%\end{array}$ \\
\hline & Komatsu (kWh/kg) \\
\hline 0 & 40 \\
10 & 45 \\
25 & 49 \\
50 & 55 \\
75 & 62 \\
90 & 70 \\
100 & 75
\end{tabular}

\begin{tabular}{ll} 
& $\begin{array}{l}\text { Union Carbide } \\
\text { Utilities Costs, } \\
\text { Electricity -- } \\
\%\end{array}$ \\
FBR (kWh/kg) \\
\hline 0 & 7.5 \\
10 & 10.0 \\
25 & 13.0 \\
60 & 15.0 \\
75 & 25.0 \\
90 & 40.0 \\
100 & 50.0
\end{tabular}

\begin{tabular}{ll} 
& $\begin{array}{l}\text { Union Carbide } \\
\text { Utilities Costs, } \\
\text { Electricity -- } \\
\text { Other Utilities } \quad(\$ / \mathrm{kg})\end{array}$ \\
$\%$ & \\
\hline 0 & $\$ 0.35$ \\
10 & $\$ 0.40$ \\
25 & $\$ 0.45$ \\
50 & $\$ 0.52$ \\
75 & $\$ 0.57$ \\
90 & $\$ 0.60$ \\
100 & $\$ 0.65$
\end{tabular}




$\% \quad \begin{aligned} & \text { Hemlock } \\ & \text { Material Costs }(\$ / \mathrm{kg})\end{aligned}$

$0 \$ \$ 2.60$

$30 \$ \$ 2.63$

$50 \$ 2.66$

$65 \$ 2.71$

$80 \$ 2.79$

$90 \$ 2.85$

$100 \$ 2.90$
Union Carbide

$\% \quad$ Material Costs ( $\$ / \mathrm{kg})$

$0 \quad \$ 1.40$

$10 \$ \$ 1.60$

$25 \$ \$ 1.80$

$50 \$ 2.10$

$75 \$ 2.25$

$90 \$ \$ 2.90$

$100 \$ 3.10$

Hemlock
Labor Costs $(\$ / \mathrm{kg})$

$0 \$ \$ 0.70$

$10 \$ 0.73$

$25 \$ \$ .74$

$50 \$ \$ 0.77$

$75 \$ 0.86$

$90 \$ \$ 0.93$

$100 \$ \$ 1.00$

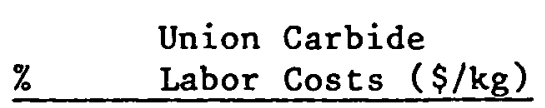

$0 \quad \$ 0.35$

$10 \$ \$ 0.44$

$25 \$ \$ .50$

$50 \$ \$ 0.60$

$75 \$ 0.78$

$90 \$ \$ .93$

$100 \$ 1.10$ 
The following economic assumptions were included in this analysis:

Variable

Equipment lifetime

Income tax rate

Other tax rate

Insurance rate

Debt percentage

Interest on debt

Percentage of annual capital that is working capital

Rate of return on equity (after taxes)

Construction lead time

Length of start-up period

Company average equipment investment tax credit rate

Contingency during construction

(equipment and facilities cost)

Miscellaneous expense percentage of revenue

Miscellaneous expense percentage of operating costs

Indirect/direct 1 abor cost ratio

Average percentage of steady-state production rate achieved during start-up

Start-up period commodity usage fraction

(above normal usage)
Assumed Value

10 years

$50 \%$

$2 \%$

$4 \%$

$16 \%$

$12 \%$

$16 \%$

$20 \%$

3 years

1 year

$11 \%$

$15 \%$

$3 \%$

$10 \%$

0.7

$3.5 \%$

1.25 